\begin{tabular}{|c|c|c|}
\hline GaM署 & $\begin{array}{l}\text { Construction and Material Journal } \\
\text { e-ISSN 2655-9625, http://jurnal.pnj.ac.id/index.php/cmj }\end{array}$ & $\begin{array}{l}\text { Volume } 2 \text { No. } 2 \\
\text { Juli } 2020\end{array}$ \\
\hline
\end{tabular}

\title{
PERENCANAAN FONDASI TIANG PANCANG PADA PROYEK TOWER 2 ARANDRA RESIDENCE
}

\author{
Zulhady Zuhri' ${ }^{1}$, Istiatun ${ }^{2}$ \\ 1)2)Jurusan Teknik Sipil, Politeknik Negeri Jakarta Jl. Prof. Dr. G. A Siwabessy, Kampus \\ Baru UI, Kota Depok, Tlp. +6221 7270036, Fax(021) 7270034, 15425 \\ Email : zuhrihady@yahoo.co.id, istiatun@sipil.pnj.ac.id
}

\begin{abstract}
The pile foundation is an sub-structure to load from the upper structure. Ultimate load carryingcapacity (qu) will be transfered into a hard soil layer by using a deep foundation system. To design the pile foundation, several methods are needed to obtain different bearing capacity values. This study determines the planned pile depth, pile dimensions and pile cap. The purpose of this final project is to plan the pile foundation for the Arandra Residance 2 tower construction project located in Cempaka Putih, Central Jakarta. The method used is the method of Meyerhof, U.S Army Corp, Tomlinson, $a$ and $\lambda$. In addition, the calculation of reinforcement, immediate settlement and settlement of primary consolidation was also carried out. The results of the calculation of bearing capacity foundation are different values. The Meyerhof Qu method is 9846,786 kN, the U.S Army Corp method Qu = 11065.11 $k N$, the Tomlinson $Q u$ method $=10409.68 \mathrm{kN}$, the method $\alpha=9558.95 \mathrm{kN}$, and the method $\lambda Q u=$ $10066.37 \mathrm{kN}$. Whereas according to Broms, the lateral bearing capacity is $10845 \mathrm{kN}$. In planning used reinforcement D25-270. Immediate settlement is $50.3 \mathrm{~mm}$, primary consolidation settlement is 9.89 $\mathrm{mm}$, and time rate of consolidation during 1.75 months.
\end{abstract}

Keywords: Foundation, driven pile, bearing capacity, settlement, primary consolidation

\begin{abstract}
ABSTRAK
Fondasi tiang merupakan fondasi yang menyalurkan beban struktur atas dan beban lainnya ke struktur lapisan tanah keras yang mempunyai daya dukung tinggi yang terletak jauh di dalam tanah. Untuk merencanakan fondasi tiang pancang diperlukan beberapa metode untuk mendapatkan nilai daya dukung yang berbeda. Studi ini menentukan kedalaman tiang pancang yang direncanakan, dimensi tiang pancang dan pilecap. Tujuan dari tugas akhir ini adalah merencanakan pondasi tiang pancang untuk proyek pembangunan tower Arandra Residance 2 yang berlokasi di Cempaka Putih, Jakarta Pusat. Metode yang digunakan adalah metode Meyerhof, U.S Army Corp, Tomlinson, $\alpha$ dan $\lambda$. Daya dukung lateral menggunakan metode Broms. Selain itu juga dilakukan perhitungan penulangan, penurunan segera, dan penurunan konsolidasi primer. Hasil perhitungan daya dukung fondasi terdapat perbedaan nilai. Metode Meyeherhof Qu $=9846.786 \mathrm{kN}$, metode U.S Army Corp Qu = $11065.11 \mathrm{kN}$, metode Tomlinson $Q u=10409.68 \mathrm{kN}$, metode $\alpha=9558.95 \mathrm{kN}$, dan metode $\lambda Q u=$ $10066.37 \mathrm{kN}$. Sedangkan menurut broms daya dukung lateral sebesar $10845 \mathrm{kN}$. Pada perencanaan digunakan tulangan D25-270. Penurunan segera terjadi sebesar $50.3 \mathrm{~mm}$, penurunan primer sebesar $9.89 \mathrm{~mm}$, dan kecepatan waktu penurunan konsolidasi selama 1.75 bulan.
\end{abstract}

Kata kunci: Fondasi, tiang pancang, daya dukung, penurunan, dan konsolidasi primer 


\section{PENDAHULUAN}

Daerah Cempaka Putih, Jakarta Pusat merupakan daerah yang secara geografis berada di dekat pantai utara Jakarta. Jenis tanah pada daerah tersebut banyak mengandung kepasiran. Oleh karena itu untuk membangun suatu bangunan tinggi pada jenis tanah tersebut dibutuhkan fondasi dalam.

Setiap konstruksi sipil harus mempunyai sesuatu elemen yang dapat mendukung bangunan tersebut untuk dapat berdiri kokoh dan kuat. Fondasi tiang digunakan untuk mendukung bangunan yang menahan gaya angkat ke atas, terutama pada bangunan-bangunan tingkat tinggi yang dipengaruhi oleh gaya-gaya penggulingan akibat beban angin (Hary Christady Hardiyatmo, 2015).

Perencanaan ini diharapkan dapat dijadikan masukan atau pertimbangan sebelum melakukan perencanaan selanjutnya, sebagai bahan referensi bagi siapa yang membaca tugas akhir ini serta yang menghadapi masalah yang sama, serta juga informasi bagi masyarakat luas dan ilmu yang bermamfaat.

\section{Landasan Teori}

1. Kapasitas daya dukung tiang

Kapasitas daya dukung ultimit neto tiang $(\mathrm{Qu})$ adalah jumlah dari tanah ujung bawah ultimate $(\mathrm{Qb})$ dan tahanan gesesk (Qs) antara sisi tiang dan tanah di sekitarnya dikurangi dengan berat sendiri tiang (Wp).Bila dinyatakan dalam persamaan,maka :

$$
\mathrm{Q}_{\mathrm{u}}=\mathrm{Qb}+\mathrm{Qs}
$$

Dengan,

$\mathrm{Q}_{\mathrm{u}} \quad=$ kapasitas dukung ultimate $(\mathrm{kN})$

$\mathrm{Qb}=$ tahanan ujung bawah ultimate $(\mathrm{kN})$

Qs = tahanan geser ultimate $(\mathrm{kN})$ a) Tahanan Ujung Ultimate $(\mathrm{Qb})$

Bila tiang terletak pada tanah lempung, kapasitas tdukung tiang umumnya dihitung pada kondisi pembebanan tak terdrainase (undrained), kecuali jika lempung termasuk jenis lempung terkonsilidasi sangat berlebihan (highly overconsolidated). Jika lempung kondisi jenuh maka $\varphi \mathrm{u}=$ $0^{\circ}$. Karena itu, sudut gesek antara tiang dan tanah $(\delta)=0$. Karena $\varphi \mathrm{u}=$ $0^{\circ}$, maka $\mathrm{Nq}=1$ dan $\mathrm{N} \gamma=0$. Berikut persamaan tahanan ujung ultimate :

$\mathrm{Qb}=\mathrm{Ab} \times \mathrm{fb}$

$\mathrm{fb}=\mathrm{Cu} \times \mathrm{Nc}+\mathrm{Pb}$

$\mathrm{Cu}=2 / 3 \times 10 \times \mathrm{N}$

Dengan ;

$\mathrm{Ab}=$ luas penampang ujung bawah

$$
\left(\mathrm{m}^{2}\right)
$$

$\mathrm{Cu} \quad=$ kohesi pada kondisi tak terdrainase (undrained)

$\mathrm{Nc}=$ faktor kapasitas daya dukung

$$
\begin{aligned}
& \mathrm{Pb}=\left(\mathrm{kN} / \mathrm{m}^{2}\right) \\
& \text { tekanan overburden ujung } \\
& \text { bawah tiang }\left(\mathrm{kN} / \mathrm{m}^{2}\right)
\end{aligned}
$$

b) Tahanan Gesek Ultimate (Qs)

Bila tiang didalam tanah kohesif, persamaan tahanan geseknya sebagai berikut :

$$
\begin{aligned}
& \mathrm{Qs}=\mathrm{As} \times \mathrm{fs} \\
& \mathrm{fs}=\mathrm{Cd}=\alpha \times \mathrm{Cu}
\end{aligned}
$$

dengan :

$\mathrm{Qs}=$ tahanan gesek dinding ultimate $(\mathrm{kN})$

fs = tahanan gesek per satuan luas ultimit $\left(\mathrm{kN} / \mathrm{m}^{2}\right)$

$\alpha=$ faktor adhesi

$\mathrm{Cd}=$ adhesi

As $=$ luas selimut tiang $\left(\mathrm{m}^{2}\right)$

Sedang pada tanah berbutir kasar, persamaan tahanan geseknya sebagai berikut :

$$
\begin{aligned}
& \text { Qs }=\text { As } \times \text { fs } \\
& \text { fs }=\mathrm{Kd} \times \mathrm{Pb} \times \operatorname{tg} \delta \\
& \text { dengan : }
\end{aligned}
$$


$\delta=$ sudut gesek dinding efektif antara sisi tiang dan tanah

$\mathrm{Kd}=$ koefisien tekanan tanah yang tergantung dari kondisi tanah

As = luas selimut tiang

$\mathrm{Pb}=$ tekanan overburden ujung bawah tiang $\left(\mathrm{kN} / \mathrm{m}^{2}\right)$

Berikut tahanan gesek dari beberapa metode :

a. Metode Meyerhof

Dalam metode Meyerhof, tahanan gesek tiang dinyatakam oleh persamaan :

$\mathrm{Qs}=\mathrm{As} \times \mathrm{fs}$

Dengan,

Qs = tahanan gesek ultimate $(\mathrm{kN})$

As = luas penampang dasar tiang $\left(\mathrm{m}^{2}\right)$

$\mathrm{Xm}=2.0$ untuk tiang pancang volume besar $=1.0$ untuk tiang pancang volume kecil

b. Metode U.S Army

Dalam metode U.S army Corps, tahanan gesek ultimate tiang dinyatakan oleh :

$$
\begin{aligned}
& \mathrm{Qs}=\mathrm{As} \times \mathrm{fs} \\
& \mathrm{fs}=\mathrm{Cd}=\alpha \times \mathrm{C}_{\mathrm{u}}
\end{aligned}
$$

Dengan,

$\mathrm{Cd}=$ adhesi antara tiang dan tanah di sekitarnya $\left(\mathrm{kN} / \mathrm{m}^{2}\right)$

$\alpha=$ factor adhesi

$\mathrm{C}_{\mathrm{u}}=$ kohesi tak terdrainase $\left(\mathrm{kN} / \mathrm{m}^{2}\right)$

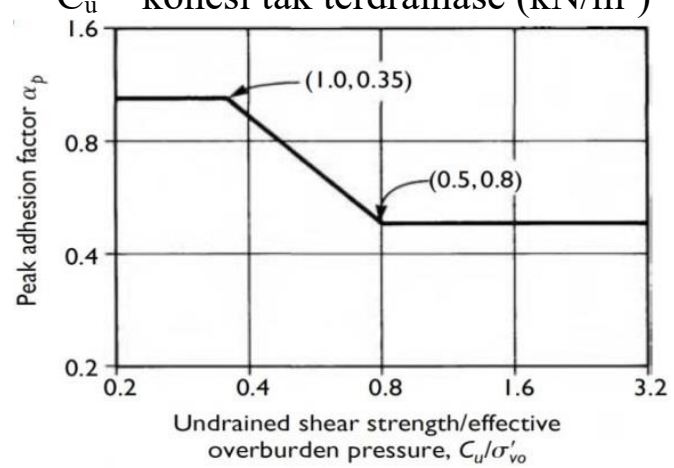

Gambar 2 Nilai $\alpha$ yang digunakan

dalam metode U.S Army Corps.

c. Metode Thomlinson

Dalam metode U.S army Corps, tahanan gesek ultimate tiang dinyatakan oleh :

$$
\begin{aligned}
& \mathrm{Qs}=\mathrm{As} \times \mathrm{fs} \\
& \mathrm{fs}=\mathrm{Cd}=\alpha \times \mathrm{C}_{\mathrm{u}}
\end{aligned}
$$

Dengan,

$\mathrm{Cd}=$ adhesi antara tiang dan tanah di sekitarnya $\left(\mathrm{kN} / \mathrm{m}^{2}\right)$

$\alpha=$ factor adhesi

$\mathrm{C}_{\mathrm{u}}=$ kohesi tak terdrainase $\left(\mathrm{kN} / \mathrm{m}^{2}\right)$

d. Metode $\alpha$

Untuk menentukan tahan gesek ultimate tiang yang dipancang di tanah lempung,digunakan faktor adhesi ( $\boldsymbol{\alpha})$ yang dikumpulkan McClelland (1974). Tahanan gesek tiang dinyatakan oleh persamaan :

$\mathrm{Qs}=\mathrm{As} \times \mathrm{fs}$

$\mathrm{fs}=\mathrm{Cd}=\alpha \times \mathrm{C}_{\mathrm{u}}$

Dimana :

fs = tahanan gesek per satuan luas

$\left(\mathrm{kN} / \mathrm{m}^{2}\right)$

$\alpha=$ faktor adhesi.

e. Metode $\lambda$

Untuk menentukan tahanan gesek ultimate yang dipancang dalam tanah lempung, digunakan cara menggunakan koefisien tak berdemensi $(\boldsymbol{\lambda})$ yang disarankan oleh Vijayvergiya dan Focht (1972).

$$
\begin{aligned}
& Q s=\mathrm{As} \times \mathrm{fs} \\
& \mathrm{fs}=\left(P_{o}{ }^{\prime}+2 C u\right)
\end{aligned}
$$

Dengan ;

fs =tahanan gesek persatuan luas $\left(\mathrm{kN} / \mathrm{m}^{2}\right)$

$\lambda=$ koefisien tak berdemensi

$P_{o}{ }^{\prime}=$ tekanan overburden efektif ratarata yang diambil dari ujung bawah tiang sampai ke permukaan tanah $\left(\mathrm{kN} / \mathrm{m}^{2}\right)$

$\mathrm{Cu}=$ kohesi tak terdrainase rata-rata di sepanjang tiang $\left(\mathrm{kN} / \mathrm{m}^{2}\right)$

As $=$ luas selimut tiang $\left(\mathrm{m}^{2}\right)$

Kraft et al. (1981) mengusulkan cara untuk memperoleh nilai $\lambda$ dengan menggunakan persamaan :

- Untuk tanah-tanah terkonsilidasi normal :

$$
\lambda=0.178-0.016 \ln \left(\pi_{3}\right)
$$

- Untuk tanah tanah terkonsilidasi berlebihan : 


$$
\begin{aligned}
\lambda & =0.232-0.032 \ln \left(\pi_{3}\right) \\
\pi^{3} & =\frac{\pi d f m a k \cdot \mathrm{Le}^{2}}{A E U}
\end{aligned}
$$

Dengan ;

$\lambda=$ koefisien yang merupakan fungsi dari penetrasi tiangg

Fmak = gesekan puncak (diambil sama dengan $\mathrm{Cu}$ rata rata) $\left(\mathrm{kN} / \mathrm{m}^{2}\right)$

Le $=$ pancang tiang yang berada di dalam tanah $(\mathrm{m})$

A = luas penampang tiang $\left(\mathrm{m}^{2}\right)$

$\mathrm{E}=$ Elastisitas bahan tiang $\left(\mathrm{kN} / \mathrm{m}^{2}\right)$

$\mathrm{U}=$ perpindahan tiang yang dibutuhkan untuk berkembangnya gesekan tiang (diambil 0.1" $=0.0025$ $\mathrm{m})$.

2. Daya dukung lateral

Daya dukung lateral menurut broms :

$\mathrm{Hu} \quad=9 \mathrm{c}_{\mathrm{u}} \cdot \mathrm{d}(\mathrm{L}-3 \mathrm{~d} .2)$

Mmak $=\mathrm{Hu}(\mathrm{L} / 2+3 \mathrm{~d} / 4)$

\section{Efisiensi Tiang Kelompok}

Menurut Converse-Labarre formula efisiensi tiang kelompok dinyatakan sebagai berikut :

$$
\begin{aligned}
& \text { Eg }=1-\theta \frac{\left(n^{I}-1\right) m+(m-1) n t}{90 m \cdot n t} \\
& \text { Dengan } \\
& \begin{aligned}
\mathrm{Eg} & =\text { efisiensi tiang kelompok } \\
\mathrm{m} & =\text { jumlah baris tiang } \\
\mathrm{n} & =\text { jumlah tiang dalam } 1 \text { baris } \\
\theta & =\operatorname{arc~tg~} \mathrm{d} / \mathrm{s} \\
\mathrm{s} & =\text { jarak pusat ke pusat tiang }(\mathrm{m}) \\
\mathrm{d} & =\text { diameter tiang }(\mathrm{m})
\end{aligned}
\end{aligned}
$$

4. Penurunan tiang pancang

a. Penurunan Primer

Vesic (1977) mengusulkan cara menghitung penurunan segera rata-rata untuk beban terbagi rata fleksibel berbentuk empat persegi panjang dan lingkaran yang terletak pada tanah elastis, homogen dan isotropis dengan tebal terbatas sebagai berikut :

$$
S s=S_{1}+S_{2}+S_{3}
$$

Dengan :

$$
\begin{aligned}
& S_{s}=\text { Penurunan segera tiang } \\
& \text { tunggal }
\end{aligned}
$$

$S_{1}=$ Penurunan akibat deformasi aksial tiang tunggal

$S_{2} \quad=$ Penurunan akibat beban ujung tiang

$S_{3}=$ Penurunan akibat beban friksi/selimut tiang.

Jika material tiang diasumsikan elastis, deformasi tiang dapat dievaluasi sesuai dengan prinsip dasar mekanika materialnya, seperti berikut :

$$
S_{1}=\frac{(Q w p+\xi Q w s) L}{A p x E P}
$$

Dengan : tian

$Q_{w p}=$ beban yang diterima ujung

$Q_{\mathrm{ws}}=$ beban yang diterima

sepanjang tiang

$L \quad=$ panjang tiang

$A_{p}=$ luas melintang tiang

$E_{p}=$ modulus elastisitas material

tiang

$\Xi \quad=$ koefisien gesekan bergantung pada distribusi gesekan selimut.

Sementara untuk penurunan yang diakibatkan beban pada ujung tiang, Vesic (1977) mengusulkan metode semi empiris dengan persamaan berikut :

$S_{2}=\frac{C_{p} \times Q_{w p}}{d \times q_{p}}$

Dengan :

$C_{\mathrm{p}}=$ koefisien empiris

$Q_{w p}=$ beban yang diterima ujung tiang

$q_{p} \quad=$ tahanan ujung tiang

$d=$ diameter tiang

b. Konsolidasi primer

Penuruan akibat konsolidasi primer dinyatakan oleh persamaan-persamaan:

$$
S_{c}=\frac{\Delta e}{1+e} H
$$

a) Untuk Lempung normally consolidated,

$$
S_{c}=\sum\left[\frac{C_{C} \Delta H}{1+e_{0}} \cdot \log \left(\frac{p_{0^{\prime}}+\Delta p}{p_{0^{\prime}}}\right)\right]
$$


1. Untuk lempung overconsolidated, harus mempertimbangkan pada dua kondisi, yaitu :

Jika $P o_{i}+\Delta P_{i} \leq P c_{i}$

$S_{c}=\sum\left[\frac{C_{r} \Delta H}{1+\theta_{0}} \cdot \log \left(\frac{p_{0^{\prime}+\Delta p}}{p_{0^{\prime}}}\right)\right]$

Jika $P o_{i}+\Delta P_{i}>P c_{i}$

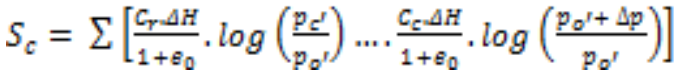

Dengan :

$S_{c}=$ penurunan konsolidasi primer

$C_{c}=$ koefisien kompresi tanah

$C_{r}=\left(\frac{1}{5} \mathrm{~s} / \cdot \frac{1}{10}\right) C_{c}$

$H=$ tebal awal lapis tanah yang mengalami konsolidasi

$e_{o}=$ angka pori awal lapis tanah yang mengalami konsolidasi $p_{o}{ }^{\prime}=$ tekanan overburdern efektif tanah titik yang ditinjau $\Delta p=$ pertambahan tegangan di titik yang ditinjau akibat beban luar.

$p_{c}{ }^{\prime}=\Delta p+p_{o}$

\section{METODE PENELITIAN}

A. Lokasi Penelitian

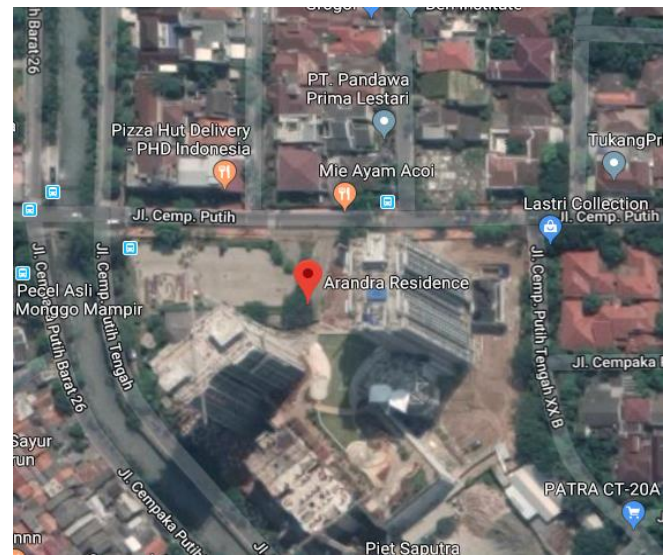

Gambar 6 lokasi Penelitian

B. Pengumpulan Data

Data yang digunakan pada tugas akhir ini, keseluruhannya merupakan data sekunder. Data sekunder dalam perencanaan ini meliputi gambar rencana, data perencanaan, data tanah yang merupakan hasil dari pengujian Standard Penetration Test (SPT) dan data Sondir.
C. Analisa Pembebanan

Pembebanan pada pilecap Apartemen Arandra Residence ini dianalisis dengan menggunakan aplikasi software struktur yaitu ETABS. Beban-beban yang bekerja pada bangunan tersebut adalah beban horizontal dan vertikal. Semua combinasi-combinasi pembebanan akan di modelkan dengan bantuan ETABS 2013.

Setelah input pembebanan dan menganalisa pembebanan akan didapatkan beban terfaktor maksimum berupa beban vertikal lateral terbesar yang akan digunakan untuk menghitung kemampuan daya dukung dan penurunan pondasi pada tugas akhir ini.

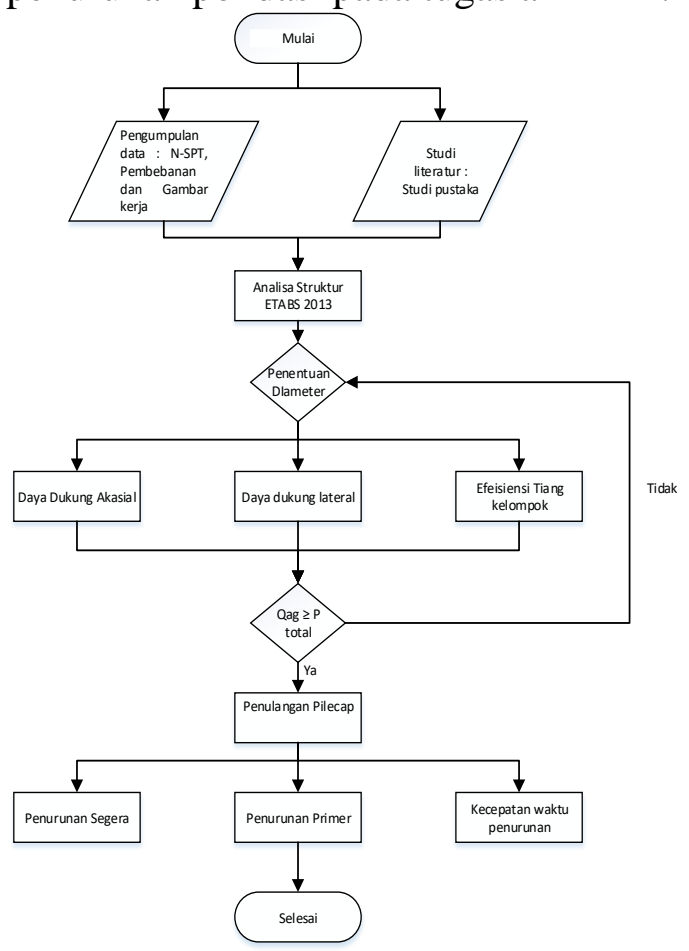

Gambar 7 Alur Penelitian

\section{HASIL dan PEMBAHASAN}

\section{A. Perhitungan Struktur Atas}

Dari hasil analisa struktur atas menggunakan 14 kombinasi diatas dengan ETABS 2013 didapatkan nilai pembebanan maksimum pada fondasi tiang pancang untuk menghitung daya dukung adalah sebagai berikut : 
a. Gaya aksial terfaktor $(\mathrm{P})=48188.3$ $\mathrm{kN}$

b. Gaya lateral terfaktor $(\mathrm{H})=631.95$ $\mathrm{kN}$

c. Momen $\operatorname{arah} \mathrm{X}(\mathrm{Mx})=1135.56 \mathrm{kNm}$

d. Momen arah Y $(\mathrm{My})=9.15 \mathrm{kNm}$

B. Perhitugan Daya Dukung Tiang Pancang

Perhitungan daya dukung aksial menggunakan beberapa metode seperti metode Meyerhof, metode U.S. Army Corps, metode Tomlinson, metode $\alpha$ dam metode $\alpha$. Sedangkan untuk perhitungan daya dukung lateral menggunakan metode Broms.

\section{1) Daya dukung aksial}

Tahanan ujung ultimate (Qb) untuk tanah kohesif didapatkan sebesar $1328.518 \mathrm{kN}$. Sedangkan untuk tahanan ultimate ujung $(\mathrm{Qb})$ untuk tanah glanular ddidapat sebesar = 2890.419 kN, Jadi Qb total sepanjang tiang sebesar $4218.937 \mathrm{kN}$.

Setelah nilai tahanan ujung ultimate (Qb) didapatkan, maka untuk mendapatkan nilai tahanan gesek ultimate (Qs) untuk tanah glanular menggunakan metode U.S Army Corp. Pada kedalaman lapisan 7 (kedalaman $16 \mathrm{~s} / \mathrm{d} 22 \mathrm{~m})$ sebesar $12217 \mathrm{kN}$ dan pada lapisan 8 (kedalaman $22 \mathrm{~s} / \mathrm{d} 28 \mathrm{~m}$ ) sebesar $11488.43 \mathrm{kN}$. Sedangkan perhitungan tahanan gesek ultimate untuk tanah kohesif sebagai berikut.

a) Metode Meyerhoff

Tabel 1. Nilai tahanan gesek ultimate

\begin{tabular}{cccccc}
\multicolumn{6}{c}{ menurut meyerhoff } \\
\hline Lapisan & $\begin{array}{c}\text { Kedalaman } \\
(\mathbf{m})\end{array}$ & $\begin{array}{c}\mathbf{A s} \\
\left(\mathbf{~ m}^{2}\right)\end{array}$ & $\begin{array}{c}\mathbf{N}- \\
\mathbf{S P T}\end{array}$ & $\begin{array}{c}\mathbf{f s}(\mathbf{k N} / \\
\left.\mathbf{m}^{2}\right)\end{array}$ & $\mathbf{Q s}(\mathbf{k N})$ \\
\hline lapisan 2 & $4-8$ & 3.768 & 20 & 40 & 150.7 \\
\hline lapisan3 & $8-10$ & 1.884 & 51 & 102 & 192.2 \\
\hline lapisan 4 & $10-12$ & 1.884 & 50 & 100.00 & 188.4 \\
\hline lapisan 5 & $12-16$ & 3.768 & 42 & 84 & 316.5 \\
\hline lapisan 7 & $16-22$ & 5.652 & 38 & 181.41 & 1139.24 \\
\hline lapisan 8 & $22-28$ & 5.652 & 29 & 222.03 & 1394.34 \\
\hline
\end{tabular}

\begin{tabular}{cccccc}
\hline Lapisan & $\begin{array}{c}\text { Kedalaman } \\
(\mathbf{m})\end{array}$ & $\begin{array}{c}\text { As } \\
\left(\mathbf{m}^{2}\right)\end{array}$ & $\begin{array}{c}\text { N- } \\
\mathbf{S P T}\end{array}$ & $\begin{array}{c}\text { fs }(\mathbf{k N} / \\
\left.\mathbf{m}^{2}\right)\end{array}$ & Qs (kN) \\
\hline lapisan 9 & $28-34$ & 5.652 & 22 & 44 & 248.7 \\
\hline \multicolumn{7}{c}{$\sum \mathbf{Q s}$} & & & 6050.11 \\
\hline
\end{tabular}

setelah nilai Qs di dapatkan, maka besar $\mathrm{Qu}$ sebesar $10269.05 \mathrm{kN}$ dan Q ijin sebasar $2616.335 \mathrm{kN}$. Jumlah tiang yang akan digunakan dari metode Meyerhof di atas sebanyak 20 tiang panjang.

b) Metode U.S Army Corp

Tabel 2. Nilai tahanan gesek tiang menurut U.S Army Corp

\begin{tabular}{|c|c|c|c|c|c|}
\hline Lapisan & $\begin{array}{c}\text { Kedalaman } \\
\text { (m) }\end{array}$ & $\begin{array}{c}\mathrm{Cu} \\
\left(\mathrm{t} / \mathrm{ft}^{2}\right)\end{array}$ & $\alpha$ & $f s$ & Qs $(\mathrm{kN})$ \\
\hline lapisan 2 & $4-8$ & 1.24 & 0.50 & 66.67 & 251.2 \\
\hline lapisan3 & $8-10$ & 3.17 & 0.50 & 170.00 & 320.9 \\
\hline lapisan 4 & $10-12$ & 3.11 & 0.50 & 166.67 & 314 \\
\hline lapisan 5 & $12-16$ & 2.61 & 0.50 & 140.00 & 527.52 \\
\hline lapisan 7 & $16-22$ & & & 201.56 & 1139.24 \\
\hline lapisan 8 & $22-28$ & & & 246.7 & 1394.34 \\
\hline lapisan 9 & $28-34$ & 1.37 & 0.50 & 73.33 & 414.48 \\
\hline \multicolumn{5}{|c|}{$\sum \mathbf{Q s}$} & 7268.432 \\
\hline
\end{tabular}

setelah nilai Qs di dapatkan, maka besar $\mathrm{Qu}$ sebesar 11487.37 kN dan Q ijin sebasar $2859.999 \mathrm{kN}$. Jumlah tiang yang akan digunakan dari metode mayerhof di atas sebanyak 17 tiang panjang.

c) Metode Tomlinson

Tabel 3. Nilai tahanan gesek tiang menurut Tomlinson.

\begin{tabular}{|c|c|c|c|c|c|}
\hline Lapisan & $\begin{array}{l}\text { Kedalaman } \\
\text { (m) }\end{array}$ & $\begin{array}{c}\mathrm{Cu} \\
\left(\mathrm{kN} / \mathrm{m}^{2}\right)\end{array}$ & $\alpha$ & $\begin{array}{c}F s \\
\left(k N / m^{2}\right)\end{array}$ & Qs $(\mathrm{kN})$ \\
\hline lapisan 2 & $4-8$ & 133.33 & 0.50 & 66.67 & 251.20 \\
\hline lapisan3 & $8-10$ & 340.00 & 0.37 & 125.8 & 237.01 \\
\hline lapisan 4 & $10-12$ & 333.33 & 0.37 & 123.33 & 232.36 \\
\hline lapisan 5 & $12-16$ & 280.00 & 0.37 & 103.6 & 390.36 \\
\hline lapisan 7 & $16-22$ & & & 201.56 & 1139.24 \\
\hline lapisan 8 & $22-28$ & & & 246.7 & 1394.34 \\
\hline lapisan 9 & $28-34$ & 146.67 & 0.39 & 57.2 & 323.29 \\
\hline \multicolumn{5}{|c|}{$\sum \mathbf{Q s}$} & 6613.01 \\
\hline
\end{tabular}


ijin sebasar $2728.914 \mathrm{kN}$. Jumlah tiang yang akan digunakan dari metode mayerhof di atas sebanyak 18 tiang panjang.

d) Metode $\alpha$

Tabel 4. Daya dukung lateral menurut $\alpha$

\begin{tabular}{ccccc}
\hline $\begin{array}{c}\text { Kedalaman } \\
(\mathrm{m})\end{array}$ & $\mathrm{Cu}\left(\mathrm{kN} / \mathrm{m}^{2}\right)$ & $\alpha$ & $\begin{array}{c}f s \\
\left(\mathrm{kN} / \mathrm{m}^{2}\right)\end{array}$ & $\mathrm{Qs}(\mathrm{kN})$ \\
\hline $4-8$ & 133.33 & 0.27 & 36 & 135.65 \\
\hline $8-10$ & 340.00 & 0.25 & 85 & 160.14 \\
\hline $10-12$ & 333.33 & 0.25 & 83.33 & 157 \\
\hline $12-16$ & 280.00 & 0.25 & 70 & 263.76 \\
\hline $16-22$ & & & 201.56 & 1139.24 \\
\hline $22-28$ & & & 246.70 & 1394.34 \\
\hline $28-34$ & 146.67 & 0.25 & 36.67 & 207.24 \\
\hline $5 \mathbf{Q s}$ & & & 5762.28 \\
\hline
\end{tabular}

setelah nilai Qs di dapatkan, maka besar $\mathrm{Qu}$ sebesar 9981.216 kN dan Q ijin sebasar $2558.768 \mathrm{kN}$. Jumlah tiang yang akan digunakan dari metode mayerhof di atas sebanyak 20 tiang panjang.

e) Metode $\lambda$

Tabel 5. Nilai tahanan gesek tiang menurut $\lambda$.

\begin{tabular}{ccccc}
\hline $\begin{array}{c}\text { Kedalaman } \\
(\mathrm{m})\end{array}$ & As $\left(\mathrm{m}^{2}\right)$ & $\begin{array}{c}\mathrm{Cu} \\
\left(\mathrm{kN} / \mathrm{m}^{2}\right)\end{array}$ & $f s\left(k N / \mathrm{m}^{2}\right)$ & Qs $(\mathrm{kN})$ \\
\hline $4-8$ & 3.768 & 133.33 & 47.77 & 180 \\
\hline $8-10$ & 1.884 & 340.00 & 109.77 & 206.8 \\
\hline $10-12$ & 1.884 & 333.33 & 107.77 & 203.04 \\
\hline $12-16$ & 3.768 & 280.00 & 91.77 & 345.79 \\
\hline $16-22$ & 5.652 & & 201.56 & 1139.24 \\
\hline $22-28$ & 5.652 & & 246.70 & 1394.34 \\
\hline $28-34$ & 5.652 & 146.67 & 51.77 & 292.60 \\
\hline \multicolumn{5}{c}{$\sum \mathbf{Q s}$} \\
\hline
\end{tabular}

setelah nilai Qs di dapatkan, maka besar $\mathrm{Qu}$ sebesar 10488.63 kN dan Q ijin sebasar $2660.251 \mathrm{kN}$. Jumlah tiang yang akan digunakan dari metode mayerhof di atas sebanyak 18 tiang panjang.

C. Perhitungan Dukung Lateral

Tiang Pancang

Diketahui : $\quad$ My $=1135.56$ kN.m

$$
\begin{aligned}
& \mathrm{d}=0.5 \mathrm{~m} \\
& \mathrm{~L} / \mathrm{D}=60>20(\text { tiang }
\end{aligned}
$$

dalam)

Tabel 6. Daya dukung lateral menurut

\begin{tabular}{|c|c|c|c|c|c|}
\hline $\begin{array}{c}\text { Kedalaman } \\
\text { (m) }\end{array}$ & $\begin{array}{c}\text { N- } \\
\text { SPT }\end{array}$ & $\begin{array}{c}\mathrm{Cu} \\
\left(\mathrm{kN} / \mathrm{m}^{2}\right)\end{array}$ & $\mathrm{My} / \mathrm{Cu} . \mathrm{D}^{3}$ & $\begin{array}{c}\mathrm{Hu} \\
\text { grafis }\end{array}$ & $\begin{array}{c}\text { Hu } \\
(\mathbf{k N})\end{array}$ \\
\hline $4-8$ & 20 & 133.33 & 315.43 & 47 & 564 \\
\hline $8-10$ & 51 & 340.00 & 123.70 & 25 & 765 \\
\hline $10-12$ & 50 & 333.33 & 126.17 & 27 & 810 \\
\hline $12-16$ & 42 & 280.00 & 150.21 & 29 & 730.8 \\
\hline $16-22$ & 38 & 253.33 & 166.02 & 31 & 706.8 \\
\hline $22-28$ & 28 & 195.56 & 215.07 & 39 & 686.4 \\
\hline $28-34$ & 20 & 146.67 & 286.76 & 44 & 4843.8 \\
\hline \multicolumn{5}{|c|}{$\sum \mathbf{Q u}$ lateral } & 4843.8 \\
\hline
\end{tabular}
broms

Tabel 7. Kapasitas daya dukung tiang kelompok

\begin{tabular}{ccc}
\hline No & $\begin{array}{c}\text { Metode yang } \\
\text { digunakan }\end{array}$ & $\begin{array}{c}\text { Qu tiang } \\
\text { kelompok }(\mathbf{k N})\end{array}$ \\
\hline $\mathbf{1}$ & $\begin{array}{c}\text { Metode } \\
\text { Meyerhoff }\end{array}$ & 130217.3 \\
\hline $\mathbf{2}$ & $\begin{array}{c}\text { Metode U.S } \\
\text { Army Corp }\end{array}$ & 145666.1 \\
\hline $\mathbf{3}$ & Metode & 137355.1 \\
\hline $\mathbf{4}$ & Tomlinson & 126567.4 \\
\hline $\mathbf{5}$ & Metode $\alpha$ & 133001.7 \\
\hline
\end{tabular}

E. Penurunan Fondasi

Tabel 8. Penurunan total

\begin{tabular}{clc}
\hline No & \multicolumn{1}{c}{ PENURUNAN } & $\begin{array}{c}\text { PENURUNAN } \\
(\mathrm{mm})\end{array}$ \\
\hline A & \multicolumn{1}{c}{ Penurunan segera } & 2.68 \\
\hline B & $\begin{array}{l}\text { Penurunan Konsolidasi } \\
\text { primer }\end{array}$ & \\
\hline 1 & lapisan 9 & 7.00 \\
\hline 2 & lapisan 10 & 2.09 \\
\hline 3 & lapisan 12 & 0.80 \\
\hline & Total Penurunan & 12.58 \\
\hline
\end{tabular}




\section{KESIMPULAN}

Berdasarkan hasil perhitungan perencanaan fondasi tiang pancang pada proyek Tower 2 Arandra Residance berdasarkan data tanah N-SPT DB 5 didapatkan hasil sebagai berikut :

1. Beban vertikal yang disalurkan dari struktur atas ke struktur bawah berdasarkan analisis menggunakan software ETABS 2013 sebagai berikut :

a. Untuk gaya aksial beban berfaktor (P) sebesar $48188.34 \mathrm{kN}$.

b. Untuk gaya lateral beban berfaktor (H) sebesar $635.95 \mathrm{kN}$.

c. Untuk momen arah $\mathrm{X}$ beban berfaktor $(\mathrm{Mx})$ sebesar 1135.56 $\mathrm{kNm}$.

d. Untuk momen arah Y beban berfaktor (My) sebesar $915 \mathrm{kNm}$.

2. Diameter tiang pancang yang dapat memikul beban aksial digunakan diameter $0.5 \mathrm{~m}$ dengan 20 jumlah tiang pancang. Diameter tersebut memenuhi syarat $\mathrm{P}_{\text {maksimal }}$ tiang pancang. Sedangkan untuk ukuran pilecap digunakan ukurun 5.8 x 5.8 meter. Ukuran pilecap tersebut didapat berdasarkan jumlah tiang pancang dan geometri yang dikemukan oleh peneliti Teng (1962).

3. Untuk penulangan pilecap digunakan tulangaan D25-270, gambar pada lampiran 8 .

4. Penurunan yang diakibat beban fondasi yang diakibat beban struktur dan beban tambahan sebagai berikut :

a. Dari hasil perhitungan penuruna segera yang dihitung menggunakan metode Vesiq terjadi penurunan sebesar 2.5 $\mathrm{mm}$.

b. Sedangkan hasil perhitungan konsolidasi primer terjadi penurunan sebesar $9.89 \mathrm{~mm}$.

c. Total penurunan sebesar 12.4 $\mathrm{mm}$.
Jadi waktu yang dibutuhkan bangunan ini dalam mengalami penurunan selama 13.5 tahun.

\section{DAFAR PUSTAKA}

[1] Adytiawanm Muh. Handy Dwi. 2016. Analisa Daya dukung Fondasi Dalam Proyek RS Pendidikan UHO. Kendari: Universitas Halu Oleo

[2] Arifin, Zainal N dan Respati N, Sri.1995 Pondasi. Bandung: Pusat Pengembangan Pendidikan Politeknik.

[3] Badan Standarisasi Nasional. 2012. SNI 1726-2013 Tentang Tata Cara Perencanaan Ketahanan Gempa Untuk Struktur Bangunan Gedung dan Non Gedung. Jakarta: BSN.

[4] Badan Standarisasi Nasional. 2013. SNI 1727-2013 Tentang Beban Minimum Untuk Perancangan Gedung dan Struktur Lain. Jakarta: BSN.

[5] Hardiyatmo, Hary Christady. 2014. Analisa dan Perancangan Fondasi I. Yogyakarta: Gadjah Mada University Press.

[6] Hardiyatmo, Hary Christady. 2015. Analisa dan Perancangan Fondasi II. Yogyakarta: Gadjah Mada University Press.

[7] Manullang, Sahat dan Iskandar, Rudi. Analisa Daya Dukung dan Penurunan Konsolidasi pada Proyek Pembangunan Jembatan Sei Deli - Belawan. Jurnal, Medan: Universitas Sumatera Utara.

[8] Direktorat Penyelidikan Masalah bangunan. 1983. Peraturan Pembebanan Indonesia Untuk Gedung 1983. Bandung: Yayasan Lembaga Penyelidikan Masalah Bangunan Gedung 